\title{
The Formation of Intercultural Communicative Competence of Future Teachers in a Trilingual Educational Environment
}

\author{
https://doi.org/10.3991/ijet.v15i17.14249 \\ Sandugash Tleubay ${ }^{(凶)}$ \\ Abai Kazakh National Pedagogical University, Almaty, Kazakhstan \\ Sandugash.tleubai@bk.ru \\ Gulmira Nurzhanova, Saltanat Ybyshova \\ Kazakh National Women's Teacher Training University, Almaty, Kazakhstan \\ Saltanat Abdigulova, Aksaule Mankesh, Toktar Kerimbekov \\ Abai Kazakh National pedagogical university, Almaty, Kazakhstan \\ Abylaikhan Ualikhanuly \\ Al Farabi Kazakh National University, Almaty, Kazakhstan
}

\begin{abstract}
This study was conducted on the junction of Cultural Linguistics, Methodology and Pedagogy. As the issue of foreign language teaching by implying cognitive lingua-cultural aspects and competence based approach in the formation of intercultural communicative competence for the requirements of the globalizing world is relatively new, the topic can be characterized by a high level of availability. This paper provides an overview of the aspects to foreign language teaching in the formation of intercultural communicative competence and it investigates the following areas: the place and importance of gaining Intercultural communicative competence in foreign language teaching to overcome misbehavior, misunderstanding arising from the cultural and mentality diversity of the people from different lingua-cultural background for cross-cultural and intercultural interaction and communication; contribution to development of cultural based exercises and activities for the aim of intercultural communicative development according to European Union Competence reference.
\end{abstract}

Keywords - Education, history, skill, attitude, awareness, trilingual education, linguistics.

\section{Introduction}

The interactions of communities and people of diverse cultures have become much more intensive than they were in the past. The most significant type of interactions of the nations and people from different lingua-cultural backgrounds is communication. 
Language is the basic tool and means of communication. Therefore, it has been acknowledged that there is an urgent call for any language to be the means of intercultural interactions and communication to integrate the globalizing world, run the business, and benefit from the boons of globalization. Intercultural communication necessitates acquiring cognition and competency in implementing the target language as a means of cross-cultural and intercultural communication effectively, appropriately and mostly verbally. Language is accepted as a cultural code of a nation: memory and history, culture and experience of cognitive activity; its worldview and mentality; the luggage of knowledge that has been transmitted from generation to generation about nature and space, phenomena and event that a group of people have had throughout the history with the interest of preserving and increasing its ethnic identity and also the means of communication. The knowledge of language and culture seems to distinguish language teaching from teaching other subjects, because language is both the subject and medium of instruction in language education.

\subsection{Aim and significance of the study}

We have focused on the integrated process of foreign language teaching with its culture for the intercultural communication competence as an object of our article. We have taken the formation process of linguistic and cultural expertise as ability to intercultural communication on the basis of original technologies and exercises by considering the students ${ }^{6}$ cultural backgrounds from different origins into account as subject of our research. We assume the ability to adequately interact with representatives of other linguistic and cultural society, allowing one to realize personal skills, and adapt to dynamically changing multicultural world resulting the process of organized and manageable transformation in training future specialists as the main idea of the research.

\section{Review of Literature}

\subsection{Central concept in competence and its history of development}

Human beings live in society in the world and need some qualifications, abilities, potentials and skills to survive and overcome difficulties they face in their lives or to fulfill their needs. They can get these qualifications throughout their lives with experiences and education. Once they get these skills, they can do or are able to solve their problems and reach their goals. If any person can succeed his/her aims, overcome his difficulties or get the knowledge of doing anything she/he is called a capable or - competent" person. It can be concluded form the explanation, given above that, the main and central concept or term in competence-based approach, is "competence" - that is mainly focused on outputs. Competence acts as the integrated characteristic of qualities of formation and preparation of graduates or is a set of abilities, considered as final qualitative result of education. There are various 
competencies such as; intellectual, methodological, personal, social and communicative competence. Our main subject is communicative competence in general and intercultural communicative competence in special. There is a necessity for definition of not only the educational and pedagogical status of competency but also structural and functional sides of it for the issue of intercultural communicative competence.

In the history of development of competence there are three main periods; 1) the early period (the beginning, 60th years of XX century when this theory has appeared as the theory of children's competence, where it in a projection to development children or babies, "ability" and "intelligence" was considered in the same row with concepts (D. Bruner, R. Sternberg, D. Elkina, etc.); The term- competence" first appeared in an article written by R.W. White in 1959 as a concept for performance motivation. 2) - the maturityll period (70th years of XX century)connected with bastings of methods of maintenance of - an individualization", "self-improvement", "self-estimation" and "self-measurement" of achievements which were widely adopted in pedagogics of the USA. The urgency of measurement and definition through "competence", stages have forced to teach the USA to expand borders of the maintenance of "competence" by inclusion not only pedagogical receptions and additional areas of knowledge, but also social indicators (a microclimate, interpersonal relations), In 1970, Craig C. Lundberg defined the concept in planning the executive development program. The term gained attraction when in 1973, David Mc Clelland, Ph.D. wrote a seminar paper entitled, "Testing for Competence rather than for Intelligence" 3 ) the third period is a stage of a socially-educational recognition (the beginning of 90th years) when on scientific horizon, there are works by definition of concept, "competence" newmodel of formation with expansion of the maintenance of formation-strategy of development of intelligence and competence. It has since been popularized by onetime fellow McBer\& Company (Currently the Hay Group ') colleague Richard Boyatz is and many others, such as T.F. Gilbert (1978) who used the concept in relevant to performance improvement. We think competency, in a general sense, can be seen as task performance. According to Pop (2010) competences are the sum of "knowledge", "skills" and "characteristics" that allow a person to perform actions and are grouped into two large categories: "general competences" and "communicative language competences" [9]. General competences comprise declarative knowledge, skills, know-how and existential competence, while communicative language competences comprise "linguistic", "sociolinguistic" and "pragmatic competences".

\subsection{Competence and performance: types of competencies}

Competency deals with the areas of personal capability that enable people to perform successfully in their jobs by completing tasks effectively. It is demonstration of knowledge and skills in meeting professional role expectations, sufficient ability or fitness for ones needs, possessing the necessary abilities to be qualified to achieve a certain goal or complete a project, the quality or state of being able or suitable for a general role; the quality or state of being competent for a general role. N. Chomsky 
(1965) introduced the distinction between "competence" and "performance". He defined competence as - "knowledge of a language, on the part of an ideal speakerhearer, that permits him/her to use his/her language and defined performance as how speakers and hearers actually produce and understand utterances, how they use their competence" [10]. He used this kind of distinction to limit the scope of linguistic theory to what he regarded as linguistic competence. We think the point, idea and distinction given here are not sufficient, need some more explanations and interpretations to draw the definite line between competence and performance.

No matter competence or performance it is, any person needs the sum of qualities and abilities to survive and overcome the difficulties, problems and also fulfill his mission and duties. He needs some knowledge and cognition about any area to be able to make right and appropriate decision, some skills to perform these decisions, some characteristics and attitudes to maintain his appropriate behaviors. As for the operational definition of competency: there are two types of competencies. According to Bunda \& Sanders (1979), one type of definitions conceives of competence - as "a hypothetical construct, the second type of competence refers to a standard of performance either implicitly or explicitly" [11].

Communicative competence is not modern but a traditionally different snapshot previously given insufficient importance. However, the convenience of communication and getting in touch with others from diverse cultures in the globalizing world has necessitated a much more serious and thorough look at the term "communicative competence". In communicative competence people and students use and need linguistic and communicative competences. Communicative and linguistic competences are so integrated to each other that separating them from each other is quite difficult. Both of them can be grouped under "language competency". The concept "CC" was developed by Hymes's critique of Chomsky. Language competence consists of not only grammatical competence, but also the ability to use language appropriately [17].

\subsection{Van Ek's model of communicative ability}

Van Ek's model of "communicative ability" (1986), cited in Byram, (1997), comprises six "competences", together with autonomy and social responsibility. His approach is like someone observing a globe by circling around it and stopping at six points. In his model, Van Ek's proposes are below [18]:

Linguistic competence: The ability to produce and interpret meaningful utterances, which are formed in accordance with the rules of the language.

Sociolinguistic competence: The awareness of ways in which the choice of language forms is determined by such conditions as setting, relationship etc.

Discourse competence: The ability to use appropriate strategy in the construction and interpretation of texts.

Strategic competence: When communication is difficult, we have to find ways of getting our meanings across or of finding out what somebody means; theseare communication strategies, such as rephrasing, assigning for clarification. 
Socio-cultural competence: Socially and culturally, languages are differently framed. Being in one specific cultural or social situation or trying to master it outside the context requires a specific reference frame, and

Social competence: Involves both the will and the skill to interact with others, involving motivation, attitudes, self-confidence, empathy and the ability to handle social situations.

Kunanbayeva S.S. (2005) offers three main types of competencies related to language competency: "competence of dialogue", "communicative competence" and "interpersonal competence" [19, p. 91]. In another classification, language competency involves three basic competencies such as: "interactive competency", "interpretive competency" and "productive competency". Actually, the both classifications given here are similar and can be compromised. Therefore, we prefer second classification to continue to discuss. Interactive competency is the ability to use language orally to interact with others in order to create social relations, express needs, understand and address needs of others and to get things to be accomplished. Joining and maintaining a discussion, dialogue and giving a speech are examples of using one's interactive competency. Interpretive competency is the ability to understand written language through reading or spoken language through listening and to interpret it appropriately. In this case, cognition plays very important role and mental process takes place. Productive competency is the ability to produce coherent, logical, appropriate and relevant messages both in writing and speaking. It is also the ability to organize thoughts and ideas appropriately and express them effectively. In order to develop interactive, interpretive and productive competencies, students also need to develop supporting competencies. One of the most important one of these supporting competencies is "linguistic competency". This competency includes the learning and mastery of grammar, pronunciation and the vocabulary needed in a given context.

This classification of competencies is quite understandable but not complete and perfect. If lingua-cultural, socio-cultural and non-verbal competences were added to the list, it would appear more promising and comprehensive. Though some are nonverbal, gestures, body language, facial expressions etc., they are culturally and socially bound and differ from one language to another. All in all, communicative competence draws on how students use the target language and what they express in different settings and interactions as appropriate. However, linguistic awareness may never be sufficient unless it is along with cultural awareness.

\subsection{Intercultural competence: Intercultural communicative competence}

Martin and Vaughn (2007) offer four components for intercultural competence that represent the key features of each of the popular definitions. They are: "(a) awareness of one's own cultural worldview, (b) attitude towards cultural differences, (c) knowledge of different cultural practices and worldviews and (d) cross-cultural skills" [21].

There is no doubt that when two or more people of different cultural backgrounds communicate, cultural barriers to communication often arise due to the differences in 
their patterns of life, social style, customs, world view, religion philosophy and so on. For successful and effective intercultural interaction, people and the students need to gain the requirements for communicative and intercultural competence. When a person acquires communicative and intercultural competencies then he is supposed to be competent in the area of intercultural communication, in other words he/she gets intercultural communicative competence.

The term "Intercultural communicative competence" (ICC) has been identified by many researchers (Kim, 1991; Schinitzer, 1995; Byram, 1997; Byram et al 2001; Byrnes, 1991; Krasnick, 1984; Baxter, 1983; Hyde, 1998; Meyer, 1991) as the ability to interact with people from another country and culture in a foreign language. In the early years of the ICC competence research, scholars tended to focus on studying one of these dimensions which led to "behavior" (e.g. Abe \& Wiseman 1983; Hammer, Gudykunst, and Wiseman 1978; Martin and Hammer 1989) "attitudinal" (Gudykunst, Wiseman and Hammer 1977) and "cognitive" (Wiseman, Hammer \& Nishida 1989; Collier et al. 1986) models of competence. Studying IC competence as a behavioral construct has become the most common approach among the scholar [22]. ICC also refers to one's "ability to communicate appropriately and effectively in intercultural interaction situations" [23].

It can be assumed that intercultural communicative competence (ICC) requires some qualifications such as skills, knowledge, attitudes, and awareness, etc. There have been many attempts to figure out and design models for ICC to illustrate what the ICC is, what components it includes and what the students need to acquire in foreign language teaching for the intercultural space of globalizing world. The most widely known and comprehensive of them is Deardroff's (2009) model. Byram offers knowledge, skills and attitudes in his model. Deardroff added critical cultural awareness in his model adapted from Byram's ones. The figure blow shows and illustrates what the sub competencies of ICC are, what qualities ICC requires and what progresses and knowledge are necessary to gain in the formation of ICC [24].

On the one hand we substantially agree what is illustrated in this model about the sub competencies and required qualities of intercultural communicative competence on the other hand we think there should be some other qualities that a person should have to be competent in the area of intercultural communication. We are impressed that the model above given assuming that everybody is same in characteristics or does not suggest any idea for that. 


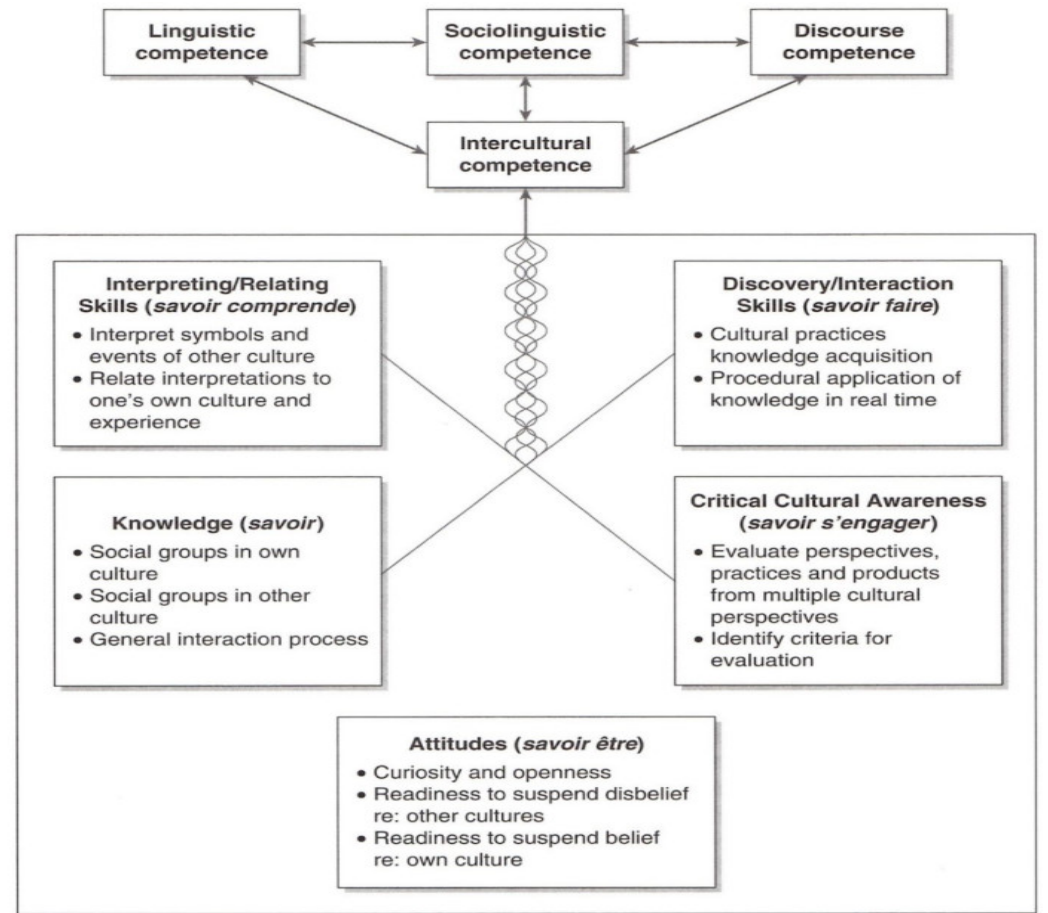

Fig. 1. Byram's model of ICC. In: Deardorff, 2009, p. 17

We think it needs some more items to explain the ICC with in all features. In this case we find Fantini's (2005) ideas more comprehensive and exclusive because he says that ICC encompasses multiple components as a complex phenomenon [25, p. 1].

These ones include:

1. A variety of traits and characteristics

2. Three areas or domains

3. Four dimensions

4. Proficiency in the host language

5. Varying levels of attainment throughout a longitudinal and developmental process

It is useful to distinguish traits (i.e., innate personal qualities) from acquired characteristics developed later in life that are related to one's cultural and situational context - a sort of "nature and nurture" distinction. This distinction is particularly important in training and educational programs because it poses the question: which abilities form part of an individual's intrinsic personality and which can be developed or modified through training and educational efforts? Commonly gained traits and/or characteristics of ICC include: flexibility, humor, patience, openness, interest, curiosity, empathy, tolerance for ambiguity and suspending judgment, among others.

ICC involves ability in three areas or domains (which, curiously, are just as important in one's own native LC1 as well). These are: 
1. The ability to establish and maintain relationships

2. The ability to communicate with minimal loss or distortion

3. The ability to collaborate in order to accomplish something of mutual interest or need

4. ICC also has four dimensions [24]: „knowledgee, (positive) attitudes/affect ${ }^{\mathrm{ee}}$, „skills ${ }^{\text {ee }}$,awareness ${ }^{\text {ee }}$. These four dimensions have already been offered in Deardorff's model adapted from Byram's once

In fact ICC includes all competences that communicative competence has: as summarized by Van Ek, includes linguistic, sociolinguistic, discourse, strategic, socio-cultural and social competence [18].Under the light of the classifications and information given above we can offer the sub competencies of ICC in brief are as follows: "Communicative (Linguistic) Competence", "Lingua-cultural competence", "Cognitive competence" and "Intercultural competence".

\section{Method}

\subsection{Research context}

As we see ICC is rather complex and complicated phenomena even to give comprehensive and satisfactory definition to it with all aspects. So, it could be understood clearly that developing ICC, an ultimate goal of foreign language teaching, is much more difficult. There have been many attempts to provide a comprehensive framework including approaches, methods, principles and classroom activities for developing ICC. The most widely known one of them is communicative language teaching which leads to acquisition of ICC. It has dominated the EFL/ESL profession since the 1970s. The communicative approach advocated by Dell Hymes $(1968,1972)$ and his supporters have gained unprecedented popularity throughout the world with the powerful influence of Britain and the United States. It has been the dominant approach in ELT in many countries where English is taught as a foreign or second language [26;27].

The communicative approach which is also known as communicative language teaching (CLT) is an approach to foreign or second language teaching characterized by meaningful communication as both its ultimate goal and major teaching method in language education. Dell Hymesis commonly credited with this trend of language teaching that moves away from traditional grammar-based approaches such as the grammar-translation and the audio-lingual methods. Communicative language teaching led to a re-examination of language learning and teaching goals, syllabuses, materials and classroom activities and has been a major cause of changes in language teaching worldwide [27]. Indeed, the influence of the communicative approach has permeated every aspect of ELT, from syllabus design, teaching methodology to teaching material selection and learning assessment.

As we know the components of ICC are often grouped in three categories (cognitive, behavioral and affective); then, the expected outcomes are usually assorted 
as "knowledge", "skills" or" "attitudes" (outputs). Depending on the desired outcome, there are different methods we can use to develop students 'ICC.

Fowler and Blohm (2004) proposed, in our opinion, the most comprehensive list of methods that are shown in table $1[30 ; 31]$.

Table 1. Fowler and Blohm's list of methods

\begin{tabular}{|c|c|c|}
\hline Category of method & Method & Outcome \\
\hline Cognitive (acquire knowledge) & $\begin{array}{l}\text { Lecture } \\
\text { Written Material } \\
\text { Computer-based material Self- } \\
\text { assessment } \\
\text { Case studies }\end{array}$ & $\begin{array}{l}\text { Knowledge } \\
\text { Knowledge } \\
\text { Knowledge, skills Knowledge, } \\
\text { skills } \\
\text { Knowledge }\end{array}$ \\
\hline Active (learn by doing) & $\begin{array}{l}\text { Simulation and games } \\
\text { Role-play } \\
\text { Exercises } \\
\end{array}$ & $\begin{array}{l}\text { Knowledge, skills, attitudes Skills, } \\
\text { attitudes } \\
\text { Knowledge, skills }\end{array}$ \\
\hline $\begin{array}{l}\text { Intercultural (develop cultural self- } \\
\text { awareness and promote } \\
\text { intercultural competencies) }\end{array}$ & \begin{tabular}{|l} 
Contrast culture \\
Critical incidents \\
Culture assimilator \\
Culture analysis \\
Cross-cultural dialogues \\
Area studies \\
Immersion \\
\end{tabular} & $\begin{array}{l}\text { Attitudes } \\
\text { Knowledge, skills, attitudes } \\
\text { Knowledge, skills, attitudes } \\
\text { Knowledge, skills Knowledge, } \\
\text { attitudes Knowledge } \\
\text { Knowledge, skills, attitudes }\end{array}$ \\
\hline Other & Art and culture & Knowledge, skills, attitudes \\
\hline
\end{tabular}

The table presents some methods, their categories that how and what kind of exercise, tasks and activities we can use them for and after using each method according to the requirements of the category of it the expected knowledge, skill and attitudes are also given. In the essence of communicative approach to foreign language teaching lays enabling the students to gain native like communicative competence or performance in the use of target language for communication and interaction. This approach considers the native like communicative competence and performance essential in the target language. To be able to reach up to this level it offers the students to fully integrate the culture of the target language. The communicative approach assumes that foreign language teaching process requires a teaching model including the lingua-cultural, socio-cultural and sociolinguistic features of the target language essential and crucial to succeed the ultimate goal which is ICC in target language.

Foreign language teaching plays a major role in preparing students to be successful inhabitants of globalizing world. The cultural content existing in foreign language teaching has been largely discussed. However, as far as we see these cultural contents or cultural based activities have not been designed in course books enough and put into practice fully in foreign language teaching. The purpose of this experimental work is to examine the influences and impacts of the use of culture-based exercises and activities in foreign language teaching in the formation of Intercultural Communicative Competence (ICC). The hundred and sixty-four students who participated in the research survey conducted at Abay Kazakh National pedagogical University in foreign languages department were randomly selected. 
The aim of this research was to find out the attitudes of both teachers and students towards foreign (English) language teaching and/or learning through culture-based activities such as: games, role plays, dialogues, discussions, comparisons of home and host cultures, video and so on before and after the experiment done. We have also tried to find out the influences and impacts of culture-based communicative exercises and activities on the progresses and achievement of the students. The stated activities were modified according the and along with the tasks in each unit of the course books, used for each subject and lesson in 2018-2019 academic year. These activities could vary from warming up, reading, listening, speaking, vocabulary and grammar to homework tasks in the units accordingly. Through practicing the aforementioned various culture-based tasks and exercises, the students also developed their communicative and linguistic competence in the target language (English), respectively. The results obtained from this research offer insights into how culturebased activities can be used not only to develop and enhance students' language skills but also their awareness of various sensitive intercultural issues.

\subsection{Participants}

The participants, in 2018-2019 academic year, consisting of 80 students, 32 males, 48 females, whose age range was between 17 and 21 , were enrolled in four different classes, 2 control and 2 experimental. The Experimental groups consisted the 18-22 students and control groups had 20 students in each. The Experimental groups consisted the18-22 students and control groups had 20 students in each.

Almost all the participants were multi-lingual; thirty of the students were ethnically Kazakh speaking Kazakh as their native language, Russian as a state language and English as a foreign language. Sixteen of them were Russian speaking Russian as a native language and English as a foreign language. The rest of the students were from Kazakhstan having various origins such as local Turkish, Uygur, Tatar, etc. speaking their mother tongues. Some of them were using a bit of Kazakh and Russian as state languages, and English as a foreign language.

The students in control groups had no extra activities related to culture but just the tasks in the books were applied and implemented. As for the experimental groups, various modified and adapted extra culture-based activities and exercises to the structure, theme and order of the tasks contained in each unit of the course books were applied as supplementary materials. In 2018-2019 academic year, "The New Inside Out" course book was used.

Since the majority of students were of Kazakh and Russian origins, we tried to make use of culture-based activities closer to their customs and traditions taking their cultural and national backgrounds too. For example, one of the units was about friends. For warm up session we gave them several questions for discussion: Do we need to correct our friends 'mistakes? How do English/Kazakh/Russian people (youngsters) make friends? How do they greet with each other's? To what extent do they share their goods? As for listening and speaking part sometimes even role play and dialogue are included. Two other questions to talk about or create sample dialogue and act out it: How do English/Kazakhstani people have conversation with 
each other when they meet or on the telephone? What do English / Kazakhstani teenagers do in their spare time? In reading task, the students were given a task to compare the facts in their countries to those in the unit. For homework, the students were given a home task to have an interview with Mr. Shustler who was working at that time at the university about the importance, role and functions of friendship in the USA.

\section{Data Collection Instruments}

\subsection{Data questionnaires}

The data was collected from the questionnaires which were given to students before and after the experiment took part and also pre and posttests which were given just to the students in the control and treatment groups. The questionnaires which were given to the students pre and post experiment, consisted of three parts; first, 8 YES/NO questions, second, 3 open ended questions and, third, 6 evaluative questions. With the questionnaires it was aimed:

1. To understand the general attitudes and habits of students towards collaborative works and activities in foreign language teaching, learning and studying.

2. To get feedback how our students and teachers liked the use of culture-based activities in foreign language teaching.

3. To get feedback on how our students have benefited from these activities.

4. To get feedback how our students got affected by culture-based activities.

5. To find out how open students concerned with and what their attitudes were towards the use of culture of target language and whether they have some fears or doubts that teaching a foreign language through cultural based activities is a kind of cultural imperialism and assimilation or not.

With YES/NO questions we aimed to find out how open the students were to the culture of the target language and to understand whether they have some fears or doubts that foreign language teaching through culture-based activities is a kind of cultural imperialism and assimilation.

In fact, both the experimental and control groups took the courses parallel and the same number and amount of activities were applied in the classroom instructions according to the contents of the course book. Additionally we tried to organize and modify the communicative activities and exercises including aspects of culture, most of which have been put into practice in the form of warm ups, discussions, speeches, dialogues, role plays and so on for the experimental groups. The overall results indicate the usefulness of culture matters for the language learning groups as one of the leading ways to foreign language teaching. According to the results, almost all students agree that the use of cultural aspects affect the learning process in the positive way.

Students made clear that by learning some features of foreigners 'behaviors depending on their cultural background different from those of the learners it 
becomes easier and interesting to be involved in the current learning process. And also, by comparing the behaviors, attitudes, reactions and the use of language depending on these kinds of cases of the native speakers with their own let them benefit from the lessons in positive way more.

\subsection{Survey results}

As a result of the survey, given to the students, it can be said that the students understand the importance and place of culture-based activities in language learning. Through using the knowledge of culture of target language, they know the importance of knowledge and competence about how to survive in different life situations and behave properly. As one of the students says "we should how to greet people of different ages from different cultures and we should also know is it acceptable or unacceptable, appropriate or not in stopping the bus in our way in order not to cause misunderstandings between two cultures". Beside this, just a few numbers of the participant students had some doubts and fears like, it is a kind of assimilation, cultural imperialism, whether necessary or not and so on, about the use of cultural based activities in teaching English.

Table 2. Number and percentages of the participant students who answered YES/NO survey

\begin{tabular}{|l|c|c|c|}
\hline & Ans. & N. Std & $\%$ \\
\hline Do you like working with other students in groups? & YES & 70 & 87,5 \\
\hline $\begin{array}{l}\text { Are you anxious or stressed when you work collaboratively with } \\
\text { your peers? }\end{array}$ & NO & 72 & 90 \\
\hline $\begin{array}{l}\text { Do cultural-based activities help you to overcome your anxiety or } \\
\text { stress? }\end{array}$ & YES & 69 & 86,3 \\
\hline $\begin{array}{l}\text { Do you like watching authentic extracts in target language about } \\
\text { your culture? }\end{array}$ & YES & 79 & 98 \\
\hline $\begin{array}{l}\text { Do you like watching authentic extracts in target language about } \\
\text { other cultures? }\end{array}$ & YES & 78 & 97,5 \\
\hline Do you like behaving as if you are a foreigner in your dialogues? & YES & 70 & 87,5 \\
\hline Do you like searching other cultures in projects? & YES & 77 & 96,3 \\
\hline Do you like being involved in discussions about other cultures? & YES & 71 & 88,7 \\
\hline
\end{tabular}




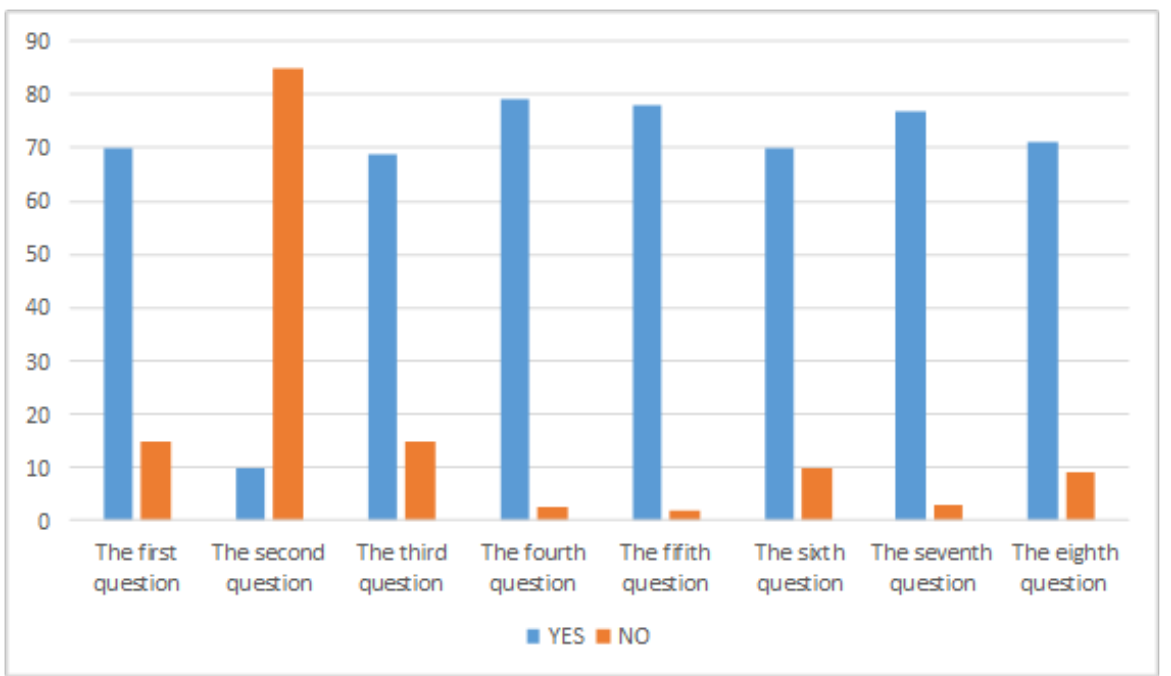

Fig. 2. The Number and percentages of the students answered YES/NO survey

These table and figure above clearly show the interest of learners towards using cultural based activities in foreign language teaching. It can confidently be said that they enjoy being involved in this atmosphere as the vast majority of them gave positive responses to each question. Summarizing the points above we came to conclusion that most of the students are aware of different cultures but still they should to be helped to master their knowledge through the professional monitoring and teaching process along with language education.

\section{Conclusion and Discussion}

\subsection{Contribution of culture-based activities}

It could be said that foreign language teaching and learning through culture-based activities is one of the most effective and interesting ways for presenting, practicing, reviewing the vocabulary and improving the learner's language and communicative competence. The major objective of this study was to figure out the effectiveness of teaching a foreign language through cultural based activities.

Culture-based activities contribute a lot in foreign language teaching if the students are given chance to practice the target language through its culture in a pleasant and friendly warm atmosphere. It is the reality that both the students and the teachers themselves demand new and creative ways of foreign language teaching and learning. As presented above, most of the culture-based (socio-cultural and lingua-cultural) activities, used in our experimental work, appreciated both by teachers and students. So, the role of cultural based activities in foreign language teaching, in our case English, cannot be ignored because every cultural activity has shown plenty of 
advantages and effectiveness in ELT in many different ways. First of all, culturebased activities bring a kind of fruitful atmosphere where students learn four skills through sharing information, discussing and interacting with each other that all the students are involved in the process of acquiring linguistic competence and thus helping themselves to retain new material easily. Secondly, cultural based activities involve the students in the task-, content and context-based activities where the goal is to set and students do their best in order to compete with each other. When they reach the aim they feel themselves happy so that they become motivated. Thirdly, the main factor of using socio-cultural activities is that they bring real world context into the classroom and enhance students' use of the target language in a flexible and communicative way. The main results of this research have implications for learners and teachers in the realm of teaching 'real 'English (the target language). It helps instructors in accomplishing their challenging tasks of foreign language teaching if the students have desire to study. Teachers can help students use different cognitive and emotive strategies to facilitate their learning styles.

\subsection{Implementation of culture - based activities into teaching process}

While working with the students we were provided many possibilities where we can use different approaches and methods. To be able to implement them correctly into teaching process we should be aware of some individual characteristics, peculiarities of cultural backgrounds of the students because there can be different nations studying in one group if we use something which is unacceptable in target culture it would cause some misunderstandings. Obviously, the teacher should keep in mind that cultural activities must be changed time by time as students can get bored very easily and these activities should be organized following all demanded conditions. It is well known that effectiveness of the lesson depends not only on the thoroughly planned lesson but on the positive atmosphere created by the teacher through different kinds of activities and tasks. As a result, we should arrange optimal conditions to provide creative atmosphere for the learning process.

We have developed the types of culture-based exercises in foreign language teaching for Intercultural Communicative Competence. We think that this typology and classification would be useful for the further research and can be used in language teaching in general and in the formation of Intercultural Communicative Competence in special.

Relying on the facts mentioned above, we can state that the use of cultural based activities is a manifold process in which you can learn a bit of psychology of the students from different cultural background because during this course you observe behaviors of students in different cultural situations.

The results of the data obtained from the data collection instruments showed that the culture-based activities have an effective influence on the development of linguistic (language)competency of students as well as developing communicative skills. First of all the teachers and then the students have an idea that the activities would be successful if they are planned step by step and presented to the students in understandable way. 
In general, aims and objectives of the study have been reached. It was proved that using cultural based activities as a valuable tool in foreign language teaching is appreciated by the majority of language teachers and students of different ages and levels. It has also become clear that both the teachers and the students have positive attitudes towards the use of cultural based activities at any time whether it is the beginning of the lesson or end. All language learners, in our case adult learners, are ready to fulfill tasks relevant to culture both for fun and benefit from foreign language teaching process. Teachers should keep in mind that these activities must be carefully planned in accordance with essence and nature of planning. In that case cultural based activities would be not just interesting for students to do but also will bring the results and achievements you expect.

\section{References}

[1] Britten D. Teacher training in ELT. Language Teaching. -1985. - №18. - P. 112-128.

[2] Erickson F. Qualitative Methods in Research on Teaching. In M. Wittrock (Ed.), Handbook of Research on Teaching. - NY: Macmillan,1986. - P.119-161.

[3] Freeman D. The "unstudied problem:" Research on Teacher Education. In D. Freeman, \& J. Richards (Eds.). Teacher Learning in Language Teaching. - Cambridge: Cambridge University Press, 1996. - P.351-378.

[4] Richards J. Beyond training: Perspectives on Language Teacher Education. - Cambridge: Cambridge University Press, 1998.

[5] Shulman L. Knowledge and teaching: Foundations of the new reform // Harvard Educational Review. - 1987. - №57 (1). - P. 1-22. https://doi.org/10.17763/haer.57.1.j463 w79r56455411

[6] Leontiev A. A. Methodology and psychology of teaching foreign languages. - Moscow: Russian language, 1991.

[7] Freeman D., Johnson K. Re-Conceptualizing the Knowledge Base of Language Teacher Education//TESOL Quarterly. -1998. - №32. - P. 397-417. https://doi.org/10.2307/358811 $\underline{4}$

[8] ValliL. (Ed.) Reflective Teacher Education: Cases and Critiques. - Albany: NY; State University of New York Press, 1992.

[9] Pop Mirela-Cristina.CNCIS MethodologyPub Date:01/01/2010. Annals of Daaam\& Proceedings Publisher // Daaam International Vienna Audience. Academic Journal. - 2008. - №11. ChomskyNoam. Aspects of the Theory of Syntax. - Cambridge: MA; MIT Press, 1965.

[10] BundaM.A., Sanders J.R. (eds.) Practices and Problems in CompetencyBased Education. UMI: A Bell and Howell Company, 1979.

[11] GarvinD. Building a Learning Organization // Harvard Business Review. -1993. - №71(4). - P. 78-91.

[12] Richards J.C., RodgersT.S. Approaches and Methods in Language Teaching (Second Edition). - Cambridge: CUP, 2001. - P.140-170.

[13] Madsen H.S. Achieving Certification through a Modified CompetencyBased TESL Teacher Education Program //TesolQuarterly. - 1975, December. Vol. 9, №4. - P. 353365. https://doi.org/10.2307/3585620 
[14] GreeneG. Mnemonic multiplication fact instruction for students with learning disabilities // Learning Disabilities Research and Practice. - 1999. - Vol.14, №3. - P. 141-148. https:// doi.org/10.1207/sldrp1403 2

[15] Sullivan Rick. Competency - based Training 1995. -2004, December - 14 http://www.repoline.jhu.edu/english/cbt/cbt.htm.

[16] GarvinD. Building a Learning Organization // Harvard Business Review. -1993. - №71(4). - P. 78-91.

[17] Hymes, D.H. (1972). On communicative competence. In J.B. Pride \& J. Holmes (Eds.), Sociolinguistics (pp. 269-293). London: Penguin.

[18] vanEk, J. A. (1986). Objectives for Foreign Language Learning, Vol. 1: Scope. Strasbourg: Council of Europe.

[19] Kunanbayeva S. S. Modern foreign language education: Methodology and theories. Almaty: Edelweiss printing house LLP, 2005. - Pp. 49-76, 200-260.

[20] Dewey J. Democracy and Education: An Introduction into the Philosophy of Education. NewYork: McMillan, 1916.

[21] MartinB.V. Strategic Diversity \& Inclusion Management magazine. - San Francisco; CA; DTUI Publications Division, 2007. - P.31-36.

[22] SebnemPenbek, DicleYurdakul A. GuldemCerit. Intercultural Communicative Competence: A study about the Intercultural Sensitivity ofUniversity students based on their education and international experiences. - Izmir: University of Economics, 2009. - P. $1-16$.

[23] Khaleeva I.I. Intercultural communication // Effective communication: history, theory. Practice: dictionary-reference / Rev. editorPanov M. I.; comp. Panov M. I., Tumina L. E.M.: LLC "Agency" KRPA Olimp", 2005. Pp. 841-844.

[24] Byram M. Teaching and assessing intercultural communicative competence. -1997. - P. 52.

[25] FantiniAlvino E. ed. About Intercultural Communicative Competence. - Brattleboro: VT; School for International Training, 2005. -P. 103.

[26] Stever H. Guyford ScienceSystems, and Society // Journal of Cybernetics. -1972. - №2(3). - P. 1-3.

[27] Zh. Kopeyev, A. Mubarakov, J. Kultan, G. Aimicheva, Y. Tuyakov. (2020). Using a Personalized Learning Style and Google Classroom Technology to Bridge the Knowledge Gap on Computer Science. International Journal of Emerging Technologies in Learning (iJET). eISSN 1863-0383, Volume 15, №2. https://doi.org/10.3991/ijet.v15 i02.11602

[28] Sh. Shuinshina, Zh. Kopeyev, Y. Tuyakov, A. Mubarakov. (2019). Continuity in education: definition, essence and analysis of the problem. Ad alta: journal of interdisciplinary research. Volume 9, Issue 1. (pp. 271-278). ISSN 1804-7890. www.doi. org/10.33543/0901

[29] Araujo, L. G. J., Bittencourt, R. A., \& Santos, D. (2018, February). An analysis of a media-based approach to teach programming to middle school students. In Proceedings of the 49th ACM Technical Symposium on Computer Science Education (pp. 1005-1010). ACM. https://doi.org/10.1145/3159450.3159526 


\section{Authors}

Sandugash Tleubay, PhD student, Abai Kazakh National Pedagogical University, Almaty, Kazakhstan. Email: sandugash.tleubai@mail.ru

Gulmira Nurzhanova, Chair of Department of Art and Culture, Kazakh National Women's Teacher Training University, Almaty, Kazakhstan. Email: nurzhanova_24@mail.ru

Saltanat Ybyshova, Candidate of pedagogical sciences, Kazakh National Women's teacher training university, Almaty, Kazakhstan. Email: Ybyshova23@gmail.com

Saltanat Abdigulova, Master of pedagogical sciences, Abai Kazakh national pedagogical university, Almaty, Kazakhstan. Email: a.sal ta@mail.ru

Aksaule Mankesh, Prof., Department of Preschool Education, Abai Kazakh National Pedagogical University, Almaty, Kazakhstan. Email: a.mankesh@mail.ru

Toktar Kerimbekov, PhD student, Abai Kazakh National Pedagogical University, Almaty, Kazakhstan. Email: tokhtarsenbekuli@gmail.com

Abylaikhan Ualikhanuly, Al Farabi Kazakh National University, Almaty, Kazakhstan

Article submitted 2020-03-15. Resubmitted 2020-05-22. Final acceptance 2020-05-22. Final version published as submitted by the authors. 